\title{
A Brief Primer on the Mental Health Impact of the Wars in Afghanistan and Iraq
}

Brett T. Litz

\section{Introduction}

The wars in Afghanistan and Iraq are the most sustained combat operations since the Vietnam War, and initial signs imply that these ongoing wars are likely to produce a new generation of veterans with chronic mental health problems associated with participation in combat. Many of the challenges facing the soldiers in Afghanistan and Iraq are stressors that have been identified and studied in veterans of previous wars (e.g., fear for own life, participation in killing).

However, these new wars also present challenges that impact the mental health problems facing veterans of these wars.

\section{What are the mental health impacts of the wars in Afghanistan and Iraq?}

Only one comprehensive study has examined the mental health impact of the wars in Afghanistan and Iraq (Hoge et al., 2004). This study evaluated soldiers' reports of their experiences in the war-zones and reports of symptoms of psychological distress. The results of this study indicated that the estimated risk for posttraumatic stress disorder (PTSD) from service in the Iraq War was 18\%, and the estimated risk for PTSD from the Afghanistan mission was $11 \%$.

Many studies indicate that more frequent and more intense involvement in combat operations increases the risk of developing chronic PTSD and associated mental health problems. Initial evidence indicates that combat operations in Iraq are very intense. Soldiers in Iraq are at risk for being killed or wounded themselves, are likely to have witnessed the suffering of others, and may have participated in killing or wounding others as part of combat operations. All of these activities have a demonstrated association with the development of PTSD. Hoge et al. (2004) indicated that $94 \%$ of soldiers in Iraq reported receiving small-arms fire. In addition, 86\% of soldiers in Iraq reported knowing someone who was seriously injured or killed, $68 \%$ reported seeing dead or seriously injured Americans, and 51\% reported handling or uncovering human remains. The majority, $77 \%$, of soldiers deployed to Iraq reported shooting or directing fire at the enemy, $48 \%$ reported being responsible for the death of an enemy combatant, and $28 \%$ reported being responsible for the death of a noncombatant. An additional set of unique stressors stems from the fact that much of the conflict in Iraq, particularly since the end of formal combat operations, has involved guerilla warfare and terrorist actions from ambiguous and unknown civilian threats. In this context, there is no safe place and no safe role. Soldiers are required to maintain an unprecedented degree of vigilance and to respond cautiously to threats. There is great concern that soldiers will mistakenly think civilians who mean them no harm are actually combatants. Soldiers also need to be careful about possibly causing collateral damage to civilians in urban environments. 
Participation in combat activities is not the exclusive source of danger and stress in a war zone. There is some evidence that the stress of war is associated with an increase in the perpetration of sexual assault and sexual harassment, with both male and female soldiers at risk for this type a victimization. In addition, a variety of environmental factors specific to each mission may contribute to the risk of mental health problems in veterans. For example, factors like poor diet, severe weather, and deficient accommodations will shape soldiers' responses to war-zone deployments. Extensive time away from family members, and the disruption of occupational goals, may serve as severe stressors, particularly for national-guard and reserve troops. In contrast, many soldiers may find meaning and gratification in their helper roles in Iraq and Afghanistan, which can potentially buffer the impact of some war-zone stressors.

\section{What is the long-term prognosis for soldiers exposed to stressors in Afghanistan and Iraq?}

Extensive research indicates that early distress and symptoms of PTSD are not very good predictors of a long-term prognosis. Thus, while Hoge et al. (2004) reported that $18 \%$ of soldiers newly redeployed from Iraq have PTSD - a rate that is alarmingly high, it is likely that this rate will decrease over time. Studies suggest that in the face of severe military service demands, including combat, most men and women do remarkably well across the lifespan. On the other hand, if the mission is experienced as a failure, if soldiers deploy more than once, if new veterans who need services do not get the support they need, or if postdeployment demands and stressors mount, the lasting mental health toll of the wars in Afghanistan and Iraq may increase over time.

For those soldiers who don't recover, the most troubling aspect of military-related PTSD is its chronic course. There is evidence that once veterans develop military-related PTSD their symptoms remain chronic across the lifespan and are resistant to treatments that have been shown to work with other forms of chronic PTSD. Thus, it is vitally important to provide early intervention to reduce the risk of chronic impairment in veterans. However, there are troubling initial signs that soldiers from the all-volunteer professional military are reluctant to seek help or that help may not be readily available to them. For example, Hoge et al. (2004) found that although approximately $80 \%$ of Iraq and Afghanistan soldiers who had a serious mental health disorder acknowledged that they had a problem, only approximately $40 \%$ stated that they were interested in receiving help and only $26 \%$ reported receiving formal mental health care. It appears that modern career soldiers are concerned about the stigma associated with mental health problems and the potential negative impact on their careers.

\section{Conclusion}

There is much that is still unknown about how soldiers adjust to the enormous demands in these new war zones. It is important to appreciate the stressors and traumas of these new wars in order to raise the awareness of civilians back home, prepare loved ones for soldiers\%o return, and meet the clinical needs of our newest veterans.

\section{Reference}

Hoge, C.W., Castro, C.A., Messer S.C., McGurk, D. Cotting, D.I. \& Koffman, R.L. (2004). 
Combat duty in Iraq and Afghanistan, mental health problems, and barriers to care. New England Journal of Medicine, 351, 13-22. 